Pacific Journal of Mathematics

ON THE DECOMPOSITION OF INFINITELY DIVISIBLE 


\title{
ON THE DECOMPOSITION OF INFINITELY DIVISIBLE CHARACTERISTIC FUNCTIONS WITH CONTINUOUS POISSON SPECTRUM, II
}

\section{ROGER CUPPENS}

\begin{abstract}
Let $f$ be an infinitely divisible characteristic function whose spectral functions are absolutely continuous functions with almost everywhere continuous derivatives. Some necessary conditions that $f$ belong to the class $I_{0}$ of the infinitely divisible characteristic functions without indecomposable factors have been obtained by Cramér, Shimizu and the author and a sufficient condition that $f$ belong to $I_{0}$ has been given by Ostrovskiy. In the present work, we prove that the condition of Ostrovskiy is not only a sufficient, but also a necessary condition that $f$ belong to $I_{0}$.
\end{abstract}

Let $f$ be the function of the variable $t$ defined by

(1)

$$
\begin{aligned}
\log f(t)= & \int_{-\infty}^{0}\left[e^{i t u}-1-i t u\left(1+u^{2}\right)^{-1}\right] \varphi(u) d u \\
& +\int_{0}^{\infty}\left[e^{i t u}-1-i t u\left(1+u^{2}\right)^{-1}\right] \psi(u) d u
\end{aligned}
$$

where log means the branch of logarithm defined by continuity from $\log f(0)=0$ and where $\varphi$ and $\psi$ are almost everywhere nonnegative and continuous functions which are defined respectively on $]-\infty, 0[$ and $] 0,+\infty[$ and satisfy the condition

$$
\int_{-\varepsilon}^{0} u^{2} \varphi(u) d u+\int_{0}^{\varepsilon} u^{2} \psi(u) d u<+\infty
$$

for any $\varepsilon>0$. If we let

$$
\begin{array}{cc}
M(x)=\int_{-\infty}^{x} \varphi(u) d u & x<0, \\
N(x)=-\int_{x}^{+\infty} \psi(u) d u & x>0,
\end{array}
$$

then we see that the conditions of the Lévy representation theorem ([4], Th. 5.5.2) are satisfied, so that $f$ is an infinitely divisible characteristic function. In [3], we have proved the following result.

If the two following conditions are satisfied:

$$
\begin{aligned}
& \varphi(u) \geqq k \text { a.e. for }-c\left(1+2^{-n}\right)<u<-c, \\
& \psi(u) \geqq k \text { a.e. for } d<u<d\left(1+2^{-n}\right),
\end{aligned}
$$

where $k, c$ and $d$ are positive constants and $n$ is a positive integer, 
then the function $f$ defined by (1) has an indecomposable factor.

The following theorem completes this result.

Theorem 1. If

$$
\psi(u) \geqq k \text { a.e. for } c<u<c\left(1+2^{-n}\right) \text { and } d<u<d\left(1+2^{-n}\right)
$$

where $n$ is a positive integer and $k, c$ and $d \geqq 2 c$ are positive constants, then the function $f$ defined by (1) has an indecomposable factor.

This theorem is an immediate consequence of the

Lemma. Let $f$ be the characteristic function defined by

$$
\log f(t)=\int_{0}^{\infty}\left(e^{i t u}-1-i t u\left(1+u^{2}\right)^{-1}\right) \alpha(u) d u
$$

where

$$
\alpha(u)= \begin{cases}c & \text { if } 1<u<\lambda \text { or } r<u<r \lambda \\ 0 & \text { otherwise }\end{cases}
$$

$c$ being a positive constant, $\lambda=1+2^{-n}$ ( $n$ positive integer $)$ and $r \geqq 2 \lambda$. Then $f$ has an indecomposable factor.

Proof. Let $\beta$ be the function defined by

$$
\beta(u)= \begin{cases}c & \text { if } 1<u<\lambda \text { or } r<u<r \lambda \\ -c \varepsilon & \text { if } \gamma<u<\delta \\ 0 & \text { otherwise }\end{cases}
$$

$(2<\gamma<\delta<2 \lambda)$ and $\alpha_{m}$ and $\beta_{m}$ be the functions defined by

$$
\begin{aligned}
& \alpha_{1}(x)=\alpha(x) ; \alpha_{m}(x)=\int_{-\infty}^{\infty} \alpha_{m-1}(x-t) \alpha_{1}(t) d t \\
& \beta_{1}(x)=\beta(x) ; \beta_{m}(x)=\int_{-\infty}^{\infty} \beta_{m-1}(x-t) \beta_{1}(t) d t .
\end{aligned}
$$

We prove easily by induction that

$$
\beta_{m}(x)=\alpha_{m}(x) \geqq 0 \quad \text { if } x \notin\left[A_{m}, B_{m}\right]
$$

where $A_{m}$ and $B_{m}$ are defined by

$$
\begin{aligned}
& A_{m}=m+2^{-n} \\
& B_{m}=m r \lambda-2^{-n} .
\end{aligned}
$$

We prove now that 


$$
\lim _{\varepsilon \rightarrow 0} \sup _{A_{m} \leqq x \leqq B_{m}}\left|\alpha_{m}(x)-\beta_{m}(x)\right|=0 .
$$

Indeed, if $\varepsilon<1$, we have

$$
\begin{aligned}
& \left|\alpha_{m}(x)\right| \leqq c^{m}(r \lambda-1)^{m-1} \\
& \left|\beta_{m}(x)\right| \leqq c^{m}(r \lambda-1)^{m-1}
\end{aligned}
$$

and from these formulae and from

$$
\begin{aligned}
& \alpha_{m}(x)-\beta_{m}(x)=\int_{-\infty}^{\infty}\left[\alpha_{m-1}(x-t) \alpha_{1}(t)-\beta_{m-1}(x-t) \beta_{1}(t)\right] d t \\
= & \int_{-\infty}^{+\infty} \alpha_{m-1}(x-t)\left[\alpha_{1}(t)-\beta_{1}(t)\right] d t-\int_{-\infty}^{+\infty}\left[\beta_{m-1}(x-t)-\alpha_{m-1}(x-t)\right] \beta_{1}(t) d t
\end{aligned}
$$

it follows by induction that

$$
\left|\alpha_{m}(x)-\beta_{m}(x)\right| \leqq \varepsilon(2 c)^{m}(r \lambda-1)^{m-1}
$$

and this implies (3).

Let now $S\left(\alpha_{m}\right)$ be the spectrum of $\alpha_{m}$. From the definition of $\alpha_{m}$, it follows easily that

$$
S\left(\alpha_{m}\right)=\bigcup_{j=0}^{m}[j+(m-j) r,(j+(m-j) r) \lambda] .
$$

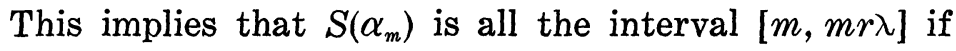

$$
m>K=\left[(r-1)\left(2^{n}+1\right)\right]
$$

(here $[x]$ means the integer part of $x$ ) and therefore

$$
\inf _{A_{m} \leqq x \leqq B_{m}} \alpha_{m}(x)>0 \quad m=K+2, K+3, \cdots .
$$

From (3) and (4), it follows that

$$
\beta_{m}(x) \geqq 0 \quad m=K+2, K+3, \cdots, 2 K+3
$$

if $\varepsilon$ is small enough. But, from the definition of $\beta_{m}$, we have for $k<m$

$$
\beta_{m}(x)=\int_{-\infty}^{\infty} \beta_{m-k}(x-t) \beta_{k}(t) d t
$$

so that, from (5)

$$
\beta_{m}(x) \geqq 0 \quad m \geqq K+2
$$

if $\varepsilon$ is small enough.

We consider now $\beta_{m}$ for $m \leqq K+1$. $\beta_{m}$ can be negative only on intervals of the kind 


$$
I=[j+k r+l \gamma,(j+k r) \lambda+l \delta]
$$

where $j$ and $k$ are nonnegative integers and $l$ a positive integer satisfying

$$
j+k+l=m
$$

and on $I$ we have

$$
\left|\beta_{m}(x)\right| \leqq \varepsilon c^{m}(r \lambda-1)^{m-1}
$$

But we have

$$
j+2 l+k r<j+k r+l \gamma<(j+k r) \lambda+l \delta<(j+2 l+k r) \lambda
$$

so that $\alpha_{m+l}$ is positive on $I$. Therefore, using (3), we have

$$
\sum_{\substack{1 \leq j \leq k+1 \\ j \neq m \rightarrow l}} \frac{\beta_{j}(x)}{j !}+\frac{\beta_{m+l}(x)}{(m+l) !}>0
$$

for $x \in I$ if $\varepsilon$ is small enough. This implies that

$$
\sum_{j=1}^{2 K+2} \frac{\beta_{j}(x)}{j !} \geqq 0
$$

for any $x$ and therefore from (6)

$$
\sum_{j=1}^{\infty} \frac{\beta_{j}(x)}{j !} \geqq 0
$$

for any $x$ if $\varepsilon>0$ is small enough.

Let now $g$ be the function defined by

$$
\log g(t)=\int_{-\infty}^{\infty}\left(e^{i t u}-1-i t u\left(1+u^{2}\right)^{-1}\right) \beta(u) d u .
$$

Then

$$
g(t)=\int_{-\infty}^{\infty} e^{i t x} d G(x)
$$

where $G$ is the function

$$
G(x)=e^{-\lambda}\left\{\chi(x+\eta)+\int_{-\infty}^{\infty}\left[\sum_{n=1}^{\infty} \frac{\beta_{n}(y+\eta)}{n !}\right] d y\right\} .
$$

Here $\chi$ is the degenerate distribution and $\lambda$ and $\eta$ are defined by

$$
\begin{aligned}
& \lambda=\int_{-\infty}^{\infty} \beta(u) d u \\
& \eta=\int_{-\infty}^{\infty} u\left(1+u^{2}\right)^{-1} \beta(u) d u .
\end{aligned}
$$


From (7), it follows that $g$ is a characteristic function if $\varepsilon$ is small enough. Since $g$ is not infinitely divisible, from the Khintchine's theorem ([4], Th. 6.2.2), $g$ has an indecomposable factor and since $g$ divides $f$, the lemma is proved.

As consequences of the Theorem 1, we obtain the following results which are respectively the results of Cramér [1] and Shimizu [6] quoted in the introduction.

CoROLlaRY 1. If in an interval [0,r] $(r>0), \psi(u) \geqq c>0$ almost everywhere, then the function $f$ defined by (1) has an indecomposable factor.

CoRollary 2. If in an interval $[r, s](s>2 r>0), \psi(u) \geqq c>0$ almost everywhere, then the function $f$ defined by (1) has an indecomposable factor.

The characterization announced in the introduction is the following.

THEOREM 2. A necessary and sufficient condition that the function $f$ defined by (1) has no indecomposable factor is the existence of an $r>0$ such that one of the two following conditions is satisfied:

(a) $\varphi(u) \equiv 0$ a.e.; $\quad \psi(u)=0$ a.e. if $u \notin[r, 2 r]$;

(b) $\psi(u) \equiv 0$ a.e.; $\quad \varphi(u)=0$ a.e. if $u \notin[-2 r,-r]$.

Proof. The sufficiency is a consequence of the Theorem 1 of Ostrovskiy [4] (see also [2], Th. 8.2), while the necessity follows immediately from the preceding theorem and from the Theorem 1 of [3] stated above.

\section{REFERENCES}

1. H. Cramér, On the factorization of certain probability distributions, Arkiv för Mat. 1 (1949), 61-65.

2. R. Cuppens, Décomposition des fonctions caractéristiques des vecteurs aléatoires, Publ. Inst. Statist. Univ. Paris (1967), 63-153.

3. - On the decomposition of infinitely divisible characteristic functions with continuous Poisson spectrum (to appear in Proc. Amer. Math. Soc.)

4. E. Lukacs, Characteristic functions, Charles Griffin and Co., Ltd, London, 1960.

5. I. V. Ostrovskiy, On the decomposition of infinitely divisible laws without gaussian factor (in Russian), Dokl. Akad. Nauk SSSR 161 (1965), 48-51.

6. R. Shimizu, On the decomposition of infinitely divisible characteristic functions with a continuous Poisson spectrum, Ann. Inst. Statist. Math. 16 (1964), 384-407.

Received May 27, 1968. This work was supported by the National Science Foundation under grant NSF-GP-6175. 



\section{PACIFIC JOURNAL OF MATHEMATICS}

\section{EDITORS}

H. ROYDEN

Stanford University

Stanford, California

\author{
R. R. Phelps \\ University of Washington \\ Seattle, Washington 98105
}

J. DugundJI

Department of Mathematics

University of Southern California

Los Angeles, California 90007

RICHARD ARENS

University of California

Los Angeles, California 90024

\section{ASSOCIATE EDITORS}

E. F. BECKenbaCH

B. H. NEUMANN

F. WOLF

K. YoSHIDA

\section{SUPPORTING INSTITUTIONS}

\author{
UNIVERSITY OF BRITISH COLUMBIA \\ CALIFORNIA INSTITUTE OF TECHNOLOGY \\ UNIVERSITY OF CALIFORNIA \\ MONTANA STATE UNIVERSITY \\ UNIVERSITY OF NEVADA \\ NEW MEXICO STATE UNIVERSITY \\ OREGON STATE UNIVERSITY \\ UNIVERSITY OF OREGON \\ OSAKA UNIVERSITY \\ UNIVERSITY OF SOUTHERN CALIFORNIA
}

\author{
STANFORD UNIVERSITY \\ UNIVERSITY OF TOKYO \\ UNIVERSITY OF UTAH \\ WASHINGTON STATE UNIVERSITY \\ UNIVERSITY OF WASHINGTON \\ $\stackrel{*}{*} \stackrel{*}{*} \stackrel{*}{*}$ AMERICAN MATHEMATICAL SOCIETY \\ CHEVRON RESEARCH CORPORATION \\ TRW SYSTEMS \\ NAVAL WEAPONS CENTER
}

The Supporting Institutions listed above contribute to the cost of publication of this Journal, but they are not owners or publishers and have no responsibility for its content or policies.

Mathematical papers intended for publication in the Pacific Journal of Mathematics should be in typed form or offset-reproduced, double spaced with large margins. Underline Greek letters in red, German in green, and script in blue. The first paragraph or two must be capable of being used separately as a synopsis of the entire paper. It should not contain references to the bibliography. Manuscripts, in duplicate if possible, may be sent to any one of the four editors. Please classify according to the scheme of Math. Rev. 36, 1539-1546. All other communications to the editors should be addressed to the managing editor, Richard Arens, University of California, Los Angeles, California, 90024.

50 reprints are provided free for each article; additional copies may be obtained at cost in multiples of 50 .

The Pacific Journal of Mathematics is published monthly. Effective with Volume 16 the price per volume (3 numbers) is $\$ 8.00$; single issues, $\$ 3.00$. Special price for current issues to individual faculty members of supporting institutions and to individual members of the American Mathematical Society: $\$ 4.00$ per volume; single issues $\$ 1.50$. Back numbers are available.

Subscriptions, orders for back numbers, and changes of address should be sent to Pacific Journal of Mathematics, 103 Highland Boulevard, Berkeley, California, 94708.

PUBLISHED BY PACIFIC JOURNAL OF MATHEMATICS, A NON-PROFIT CORPORATION

Printed at Kokusai Bunken Insatsusha (International Academic Printing Co., Ltd.), 7-17, Fujimi 2-chome, Chiyoda-ku, Tokyo, Japan. 


\section{Pacific Journal of Mathematics \\ Vol. 29, No. $3 \quad$ July, 1969}

Herbert James Alexander, Extending bounded holomorphic functions from certain subvarieties of a polydisc ...................... 485

Edward T. Cline, On an embedding property of generalized Carter

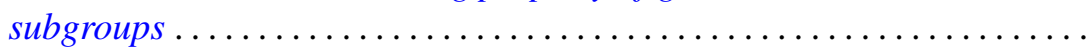

Roger Cuppens, On the decomposition of infinitely divisible characteristic functions with continuous Poisson spectrum. II ...............

William Richard Emerson, Translation kernels on discrete Abelian

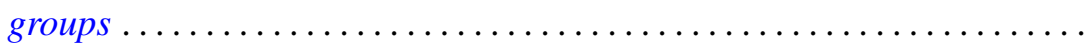

Robert William Gilmer, Jr., Power series rings over a Krull domain ....... 543

Julien O. Hennefeld, The Arens products and an imbedding theorem ...... 551

James Secord Howland, Embedded eigenvalues and virtual poles ........ 565

Bruce Ansgar Jensen, Infinite semigroups whose non-trivial homomorphs are all isomorphic .............................. 583

Michael Joseph Kascic, Jr., Polynomials in linear relations. II .......... 593

J. Gopala Krishna, Maximum term of a power series in one and several

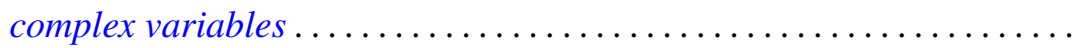

Renu Chakravarti Laskar, Eigenvalues of the adjacency matrix of cubic lattice graphs ...................................

Thomas Anthony Mc Cullough, Rational approximation on certain plane

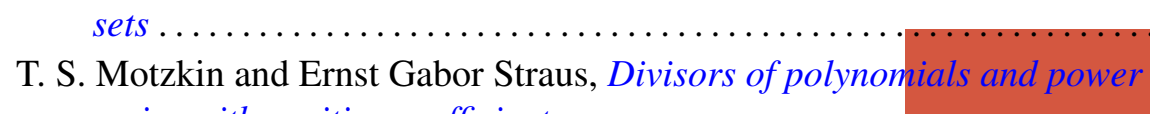
series with positive coefficients .

Graciano de Oliveira, Matrices with prescribed characteristic polynomial and a prescribed submatrix.

Graciano de Oliveira, Matrices with prescribed characteristic polynomial and a prescribed submatrix. II .

Donald Steven Passman, Exceptional 3/2-transitive permutation groups .................................

Grigorios Tsagas, A special deformation of the metric with no negative sectional curvature of a Riemannian space............

Joseph Zaks, Trivially extending decompositions of $E^{n}$ 